\title{
Simple delayed discrimination of tastes in the rat
}

\author{
DEBORAH A. OLIN and ANTHONY L. RILEY \\ The American University, Washington, D.C.
}

\begin{abstract}
Although taste memory has been extensively studied within the context of long-delay taste aversion learning, little attention has been devoted to taste memory within more traditional memory designs, for example, simple delayed discriminations. This was examined in the present experiment. Specifically, following taste discrimination training during which responding was reinforced following exposure to only one of two tastes, delays were imposed between sampling of the initial taste and the opportunity to respond. On the average, subjects were able to perform the simple delayed taste discrimination with an accuracy of $80 \%$ or better at a delay of 45 sec. Discrimination performance returned to chance at an average delay of $58 \mathrm{sec}$. Taste memory within the simple delayed discrimination paradigm is discussed and compared with other assessments of short-term memory in the rat and other species.
\end{abstract}

Although considerable attention has been devoted to taste memory, its analysis has been primarily restricted to the taste aversion design (see Domjan, 1983, 1985; Garcia, Ervin, \& Koelling, 1966; Nachman, 1970; Revusky, 1968; Riley, Dacanay, \& Mastropaolo, 1984; Riley \& Tuck, 1985a; Smith \& Roll, 1967; Westbrook \& Homewood, 1982; see also Biederman, Milgram, Heighington, Stockman, \& O'Neill, 1974; Bureš \& Burešova, 1977; Rzoska, 1954). To assess taste memory within a more traditional memory paradigm, the present study utilized a simple delayed discrimination procedure (see Honig \& Wasserman, 1981). Specifically, following taste discrimination training during which responding was reinforced following exposure to only one of two tastes, delays were imposed between sampling of the initial taste and the opportunity to respond.

Because long-delay taste aversion learning has often been presented and discussed as a specialized adaptation (see Garcia \& Ervin, 1968; Revusky \& Garcia, 1970; Riley \& Tuck, 1985b; Rozin \& Kalat, 1971; though see Klosterhalfen \& Klosterhalfen, 1985; Logue, 1979; Spiker, 1977), the present study should allow for a preliminary assessment of the general characteristics of taste memory. Furthermore, because the simple delayed discrimination baseline has been widely used to assess short-term memory in a range of species (D'Amato, 1973; Herman \& Gordon, 1974; Roberts \& Grant, 1976) and with stimuli from different stimulus modalities (Cohen, Escott, \& Ricciardi, 1984; D'Amato, 1973; Grant, 1982; Wallace, Steinert, Scobie, \& Spear, 1980), the present study should also allow for comparisons of taste memory in the rat with these other assessments.

The authors would like to thank Robert Colnes for his technical assistance throughout the conduct of this research. Requests for reprints should be sent to Deborah A. Olin, Psychopharmacology Laboratory, Department of Psychology, The American University, Washington, DC 20016.

\section{METHOD}

\section{Subjects}

The subjects were 4 experimentally naive female rats of LongEvans descent, approximately 90 days of age at the beginning of the experiment. They were housed individually in wire-mesh cages and were maintained on a 12-h-light/12-h-dark cycle (lights on at $0800 \mathrm{~h}$ ). The subjects were given ad-lib access to food, but access to water only during experimental sessions.

\section{Apparatus}

Experimental sessions were conducted in a single Plexiglas chamber $(25 \times 30 \times 18 \mathrm{~cm})$. In the front wall of the chamber were three equally spaced holes through which stainless steel drinking tubes protruded. Taste stimuli and water reinforcers were delivered via solenoid valves through the center and right tubes, respectively. Responses (licks) were registered by a drinkometer (Lafayette Model 58008) when a circuit was completed between the floor of the chamber and either tube. All schedule contingencies were programmed on and all responses were recorded by a TRS-80 Model III microcomputer interfaced to the chamber via an Alpha Interfacer 80. (For a detailed description of the apparatus, see Mastropaolo, Dacanay, Luna, Tuck, \& Riley, 1984.)

\section{Procedure}

Response shaping. On Day 1, water-deprived subjects were placed into the experimental chamber, during which time the light over the right (operant) drinking tube was illuminated. Each lick on this tube operated a valve and delivered a 0.02 -cc drop of tap water, that is, continuous reinforcement (CRF). This session was terminated after 500 responses.

On the following session, subjects were shaped to lick on a fixed ratio (FR) 20 schedule on the illuminated operant tube. Completion of the FR 20 resulted in delivery of a 0.02 -cc tap-water reinforcer at this tube, following which the light on the operant tube was darkened and a time-out light was illuminated for 2 sec. Licks during this period reset the time-out clock. This time-out period gradually increased from 2 to $10 \mathrm{sec}$ during this session.

On the next day, a discrete trial procedure was initiated. At the onset of a trial, the light over the center (stimulus) tube was illuminated. A single lick on this tube turned off this light and delivered a 0.01-cc drop of a flavored solution, either sodium saccharin ( $S$, $0.1 \% \mathrm{w} / \mathrm{v}$, Fisher Purified) or sodium chloride (N, 0.9\% w/v, Fisher Purified). Concurrent with the termination of the stimulus 
light and delivery of the taste, the light over the operant tube was illuminated. Following either taste stimulus, completion of the FR 20 on this tube within $8 \mathrm{sec}$ (limited hold) resulted in the delivery of a 0.02-cc drop of tap water. Completion of the FR 20 or the lapse of $8 \mathrm{sec}$, whichever came first, was followed by darkening of the operant tube and the illumination of the time-out light for $10 \mathrm{sec}$, during which time licks on the stimulus tube reset the time-out clock. The next trial was initiated at the end of this time-out period.

Phase 1: Discrimination training. As above, during the illumination of the stimulus tube, a single lick resulted in the delivery of either S or N. Concurrent with the fifth lick on this tube, the stimulus light and houselight were darkened for a $1-\mathrm{sec}$ period. Following this delay, the stimulus tube and houselight were again illuminated and a single lick on the stimulus tube resulted in delivery of another taste (either $\mathrm{S}$ or $\mathrm{N}$ ). The stimulus tube was then darkened and the light over the operant tube was illuminated. If the initial stimulus of the two-taste sequence was saccharin, for example, S-S or S-N (Sd), completion of the FR20 on the operant tube within $8 \mathrm{sec}$ was reinforced with a $0.02-\mathrm{cc}$ drop of tap water. If the initial stimulus of the sequence was sodium chloride, for example, N-S or N-N (S $\Delta)$, further responses were not reinforced. In either the $S d$ or the $S \Delta$ condition, completion of the FR 20 or the lapse of $8 \mathrm{sec}$, whichever came first, initiated the 10 -sec timeout period. On the average, $50 \mathrm{Sd}$ and $50 \mathrm{~S} \Delta$ trials were randomized over the session, with the restriction that no more than three Sd or three $\mathbf{S} \Delta$ trials could occur consecutively.

After 7 days, the discrimination procedure was altered such that an additional taste (again either $\mathrm{S}$ or $\mathrm{N}$ ) was presented concurrently with the fifth lick and the termination of the stimulus light and houselight (i.e., at the outset of the 1-sec delay). This taste served to randomize the aftertaste that would be available following the delay. As above, only the initial taste stimulus was relevant to the discrimination task

Phase 2: Memory assessment with titrating delays. During this phase, the specific procedure was identical to that described above, except that the delay interval between the second and third tastes was gradually increased according to a specific titration procedure. If discriminative performance was correct on four consecutive trials, then the delay interval was incremented by $2 \mathrm{sec}$. If performance was incorrect on two consecutive trials, then the delay interval was decremented by $2 \mathrm{sec}$ (to a minimum delay interval of $2 \mathrm{sec}$ ). Each successive session was begun at the same delay as the preceding session, unless performance had been above $80 \%$ correct on the preceding day. In this case, delays began titrating at $5 \mathrm{sec}$ longer than the final delay of the preceding day. The subjects were maintained on this titration procedure until they were no longer able to maintain discriminative performance at or above $80 \%$ correct.

Phase 3: Memory assessment with constant delays. The specific procedure in this phase was identical to that described above, except that on each day of this final phase the length of the delay was constant for the entire session. The specific delay for each session was chosen from the range of delays in the preceding phase. The sequence of delays over days was determined randomly for each subject.

\section{RESULTS}

The primary data reported are the overall percentages of correct trials and the percentages of correct $\mathrm{Sd}$ and $\mathrm{S} \Delta$ trials occurring in each session. For each session, the overall percentage of correct trials was determined by dividing the number of correct trials by the total number of trials. The percentage of correct $\mathrm{Sd}$ and $\mathrm{S} \Delta$ trials was determined by dividing the number of correct trials for each stimulus condition by the total number of trials in that condition. For Sd trials, completion of the FR20 within $8 \mathrm{sec}$ was recorded as correct; for $\mathrm{S} \Delta$ trials, the lapse of $8 \mathrm{sec}$ without the completion of the FR20 was recorded as correct.

\section{Phase 1: Discrimination Training}

Figure 1 shows the overall percentage of correct trials for individual subjects over the 12 days of discrimination training. As illustrated, on Day 1 of this phase overall performance was at or near chance (range of 50\%-56\% correct trials). Within 7 days, overall performance was at least $80 \%$ correct for all subjects. When an additional taste was presented at the outset of the 1-sec delay (Day 8), overall performance decreased from a range of $80 \%-82 \%$ to $56 \%-68 \%$ correct. Within 5 days, overall performance was again above $80 \%$ correct for all subjects (see Figure 1, Days 8-12).

Figure 2 shows the percentage of correct $\mathrm{Sd}$ and $\mathrm{S} \Delta$ trials for individual subjects over these same 12 days. On Day 1 of discrimination training, the percentage of correct Sd trials $(76 \%-100 \%)$ was higher than that for the $S \Delta$ condition $(0 \%-26 \%)$. With training, the percentage of correct $S \Delta$ trials increased (see Days $1-7$ ). When the additional taste was given at the outset of the 1-sec delay (Day 8), the range of percent-correct Sd trials remained high $(88 \%-99 \%)$. However, the range of percent-correct $\mathrm{S} \Delta$ trials dropped considerably $(24 \%-36 \%)$. With training, the percent-correct $S \Delta$ trials increased (see Figure 2, Days 8-12).

\section{Phase 2: Memory Assessment With Delay Titration}

Upon the introduction of a 2-sec starting delay, overall performance was disrupted for all subjects to a range of $51 \%-58 \%$ of correct trials. Within $2-15$ days, all subjects had reattained the $80 \%$ correct criterion (range of $80 \%-86 \%$ correct). For some subjects, the introduction of longer starting delays occasionally disrupted performance. Generally, however, criterion responding was reattained within 3 days. Although the range of delays within a session and over subsequent sessions varied for individual subjects, all subjects were able to perform above criterion with a starting delay of $20 \mathrm{sec}$. With the introduction of sufficiently long starting delays, subjects were no longer able to reattain overall performance above criterion. The final ranges of within-session intervals for which Subjects 1, 3, 5, and 7 were performing above criterion were $45-60,20-30,35-42$, and $35-46 \mathrm{sec}$, respectively.

There was no specific pattern in the percentage of correct $S d$ or $S \Delta$ trials during this titration phase. Only at the longest delay intervals, when overall performance deteriorated, did a pattern emerge. For Subjects 1, 5, and 7 , the percentage of correct $\mathrm{Sd}$ trials remained high and 

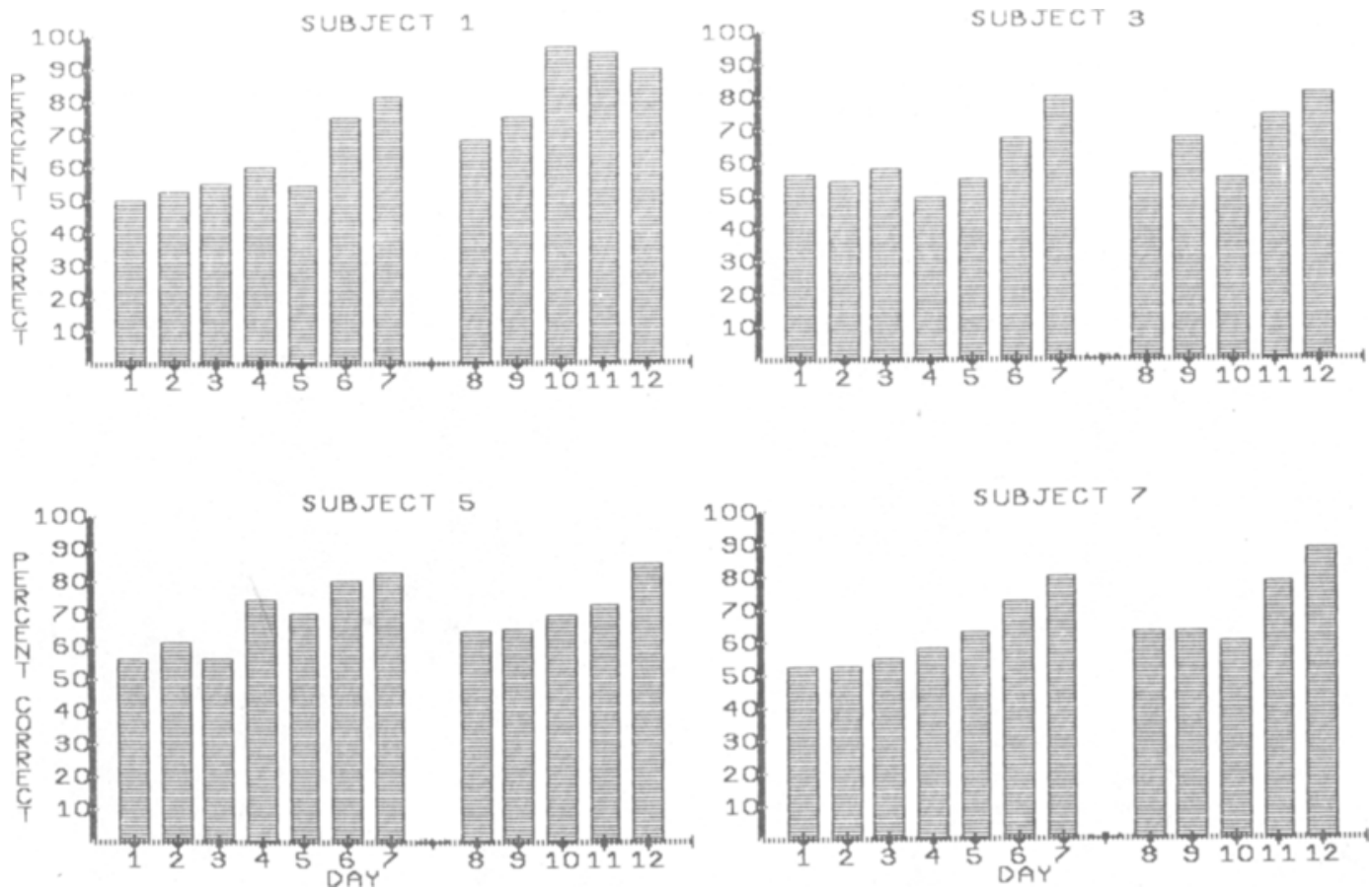

Figure 1. Overall percentage of correct trials for individual subjects during discrimination training with two tastes (Days 1-7) and with three tastes (Days 8-12).
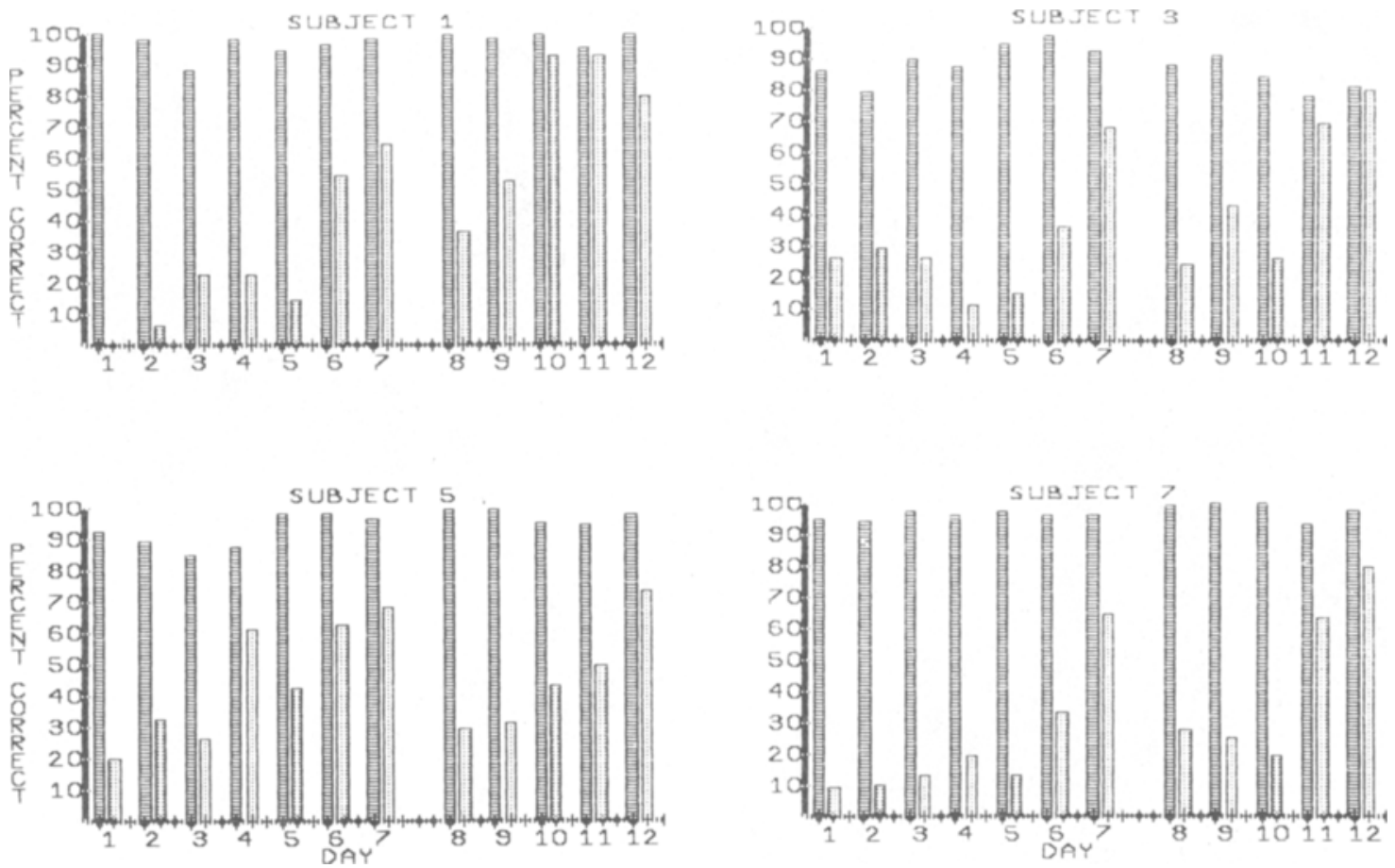

Figure 2. Percentage of correct Sd (lined bars) and $S \Delta$ (stippled bars) trials for individual subjects during discrimination training with two tastes (Days 1-7) and with three tastes (Days 8-12). 
the percentage of correct $S \Delta$ trials decreased. For Subject 3 , decreases in performance were not systematically related to either the $\mathrm{Sd}$ condition or the $\mathrm{S} \Delta$ condition.

\section{Phase 3: Memory Assessment With Constant Delays}

Figure 3 shows the overall percentage of correct trials for each session during this phase. Although the specific delays were random over sessions, the data are presented in order of sequentially increasing delay lengths. As illustrated, all subjects performed at above $80 \%$ correct at shorter delays and showed a decrease in the percentage of correct trials at longer delays. For Subjects 1, 3, 5, and 7 , respectively, overall performance was above criterion at delays of $54,32,48$, and $44 \mathrm{sec}$ and did not reach near-chance levels of performance until delays of $74,42,58$, and $56 \mathrm{sec}$

Figure 4 shows the percentage of correct $\mathrm{Sd}$ and $\mathrm{S} \Delta$ trials for each subject during Phase 3 . At shorter delays, the percentages of correct $S d$ and correct $S \Delta$ trials were high. At longer delays, however, specific patterns of Sd and $\mathrm{S} \Delta$ performance emerged. For Subjects 1,5 , and 7 , there was a decrease in the percentage of correct $S \Delta$ trials, but their percentage of correct Sd trials remained high; that is, subjects tended to complete the FR 20 on both Sd and $S \Delta$ trials. For Subject 3, this pattern was reversed; that is, this subject did not respond on either $\mathrm{Sd}$ or $\mathrm{S} \Delta$ trials.

Table 1 presents the mean number of licks for both stimulus conditions during Phase 3 for each subject. As illustrated, at the shorter delays all subjects tended to com- plete the FR20 requirement following presentation of the Sd, making a mean of approximately 19.7 licks. Following presentation of the $S \Delta$, all subjects tended to inhibit responding, making a mean of approximately 7 licks. With the longer delays, differences emerged among subjects in the pattern of $S d$ and $S \Delta$ responding. Subjects 1,5 , and 7 continued to make a mean of approximately 18.6 licks following presentation of the $\mathrm{Sd}$, but increased the mean number of licks in the $S \Delta$ condition to approximately 16.2. The pattern for Subject 3 was reversed. This subject continued to inhibit responding following presentation of the $S \Delta$ (1 lick per trial), but its responding in the $\mathrm{Sd}$ condition decreased to a mean of 4.7 licks per trial.

\section{DISCUSSION}

As illustrated, rats were able to perform the delayed taste discrimination above criterion at an average delay of $45 \mathrm{sec}$. Only at the more extended delays (on average $58 \mathrm{sec})$ did discriminative performance reach chance levels. These delays are quite comparable to those reported with rats and other species when different sensory modalities have been examined within the delayed discrimination procedure (see Cohen et al., 1984; D'Amato \& Worsham, 1974; Heise, Keller, Khavari, \& Laughlin, 1969; Herman \& Gordon, 1974; Honig \& Wasserman, 1981; Pontecorvo, 1983; Wallace et al., 1980).

Although these delays are comparable to those previously reported, several aspects of the delays should be noted. First, the delays were averages of the performance for four individual animals. As described, there was con-
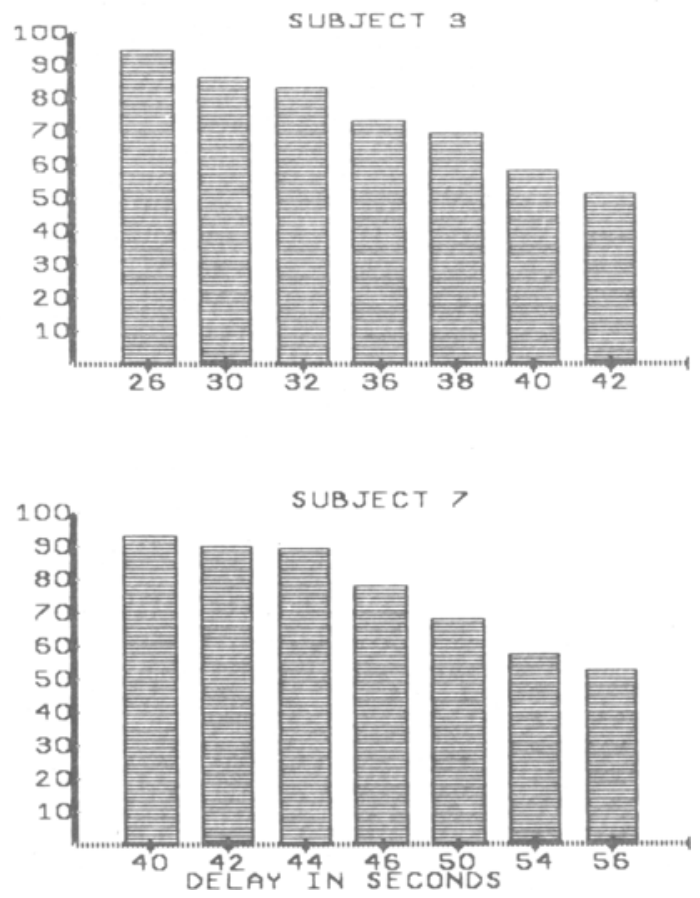

Figure 3. Overall percentage of correct trials for individual subjects during Phase 3: Memory Assessment. (Delays were constant for any specific session during this phase.) 

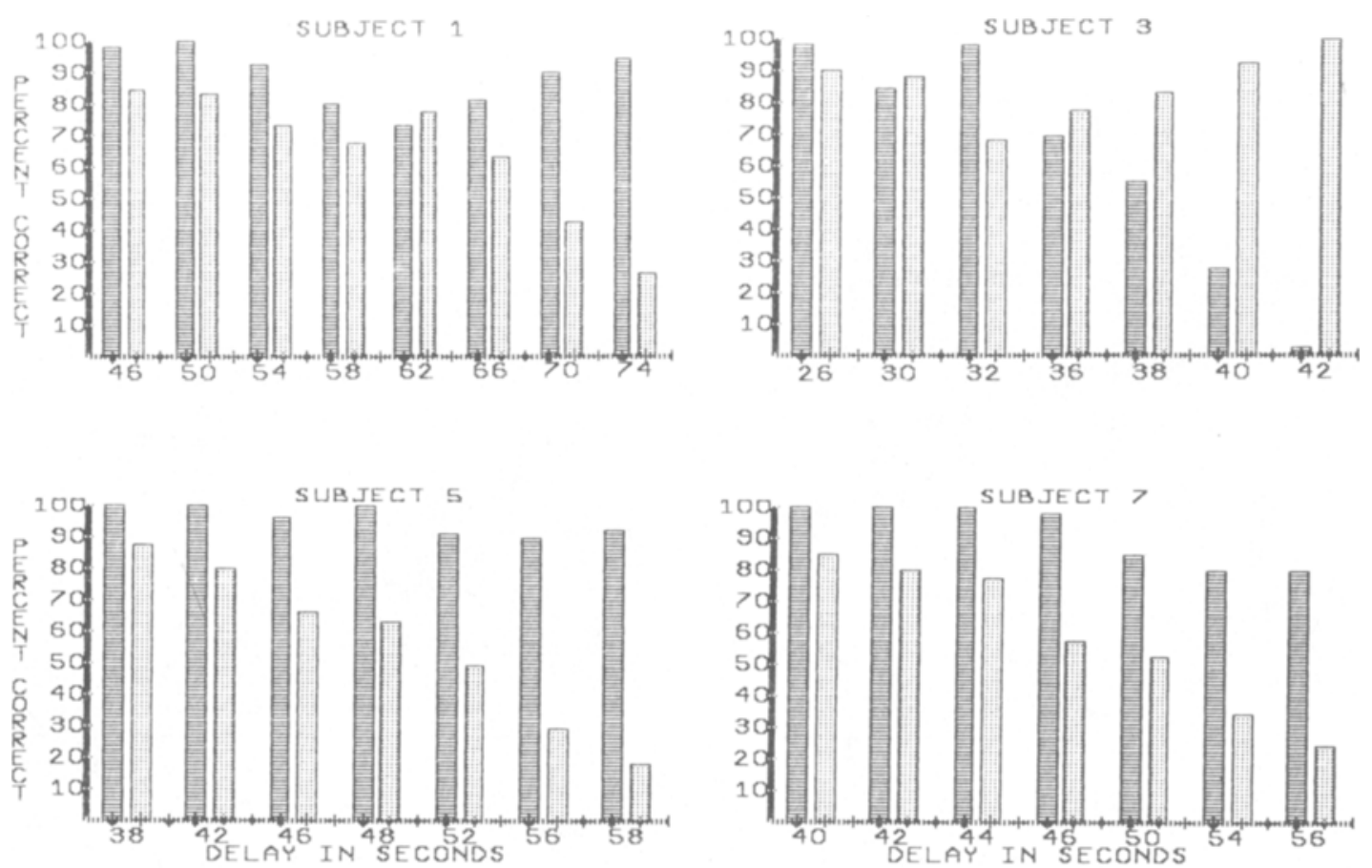

Figure 4. Percentage of correct $S d$ (lined bars) and $S \Delta$ (stippled bars) trials for individual subjects during Phase 3: Memory Assessment. (Delays were constant for any specific session during this phase.)

Table 1

Mean Number of Licks per Trial for Individual Subjects During Phase 3: Memory Assessment

\begin{tabular}{|c|c|c|c|}
\hline \multirow[b]{2}{*}{ Subject } & \multirow{2}{*}{$\begin{array}{c}\text { Delay } \\
\text { (seconds) }\end{array}$} & \multicolumn{2}{|c|}{ Licks } \\
\hline & & Sd & $\mathrm{S \Delta}$ \\
\hline 1 & $\begin{array}{l}46 \\
50 \\
54 \\
58 \\
62 \\
66 \\
70 \\
74\end{array}$ & \begin{tabular}{l|l|}
19.6 & \\
20.0 & 18.8 \\
17.9 & \\
16.3 & 18.8 \\
18.3 & \\
19.2 &
\end{tabular} & $\begin{array}{r}4.9 \\
8.2 \\
5.6 \\
14.5 \\
3.0 \\
9.0 \\
12.5 \\
15.1\end{array}$ \\
\hline 3 & $\begin{array}{l}26 \\
30 \\
32 \\
36 \\
38 \\
40 \\
42\end{array}$ & \begin{tabular}{r|r|}
19.3 & 17.8 \\
17.8 \\
19.6 \\
18.6 \\
16.4 \\
11.7 \\
4.7
\end{tabular} & $\begin{array}{l}3.8 \\
2.6 \\
7.6 \\
7.5 \\
6.7 \\
4.5 \\
1.0\end{array}$ \\
\hline 5 & $\begin{array}{l}38 \\
42 \\
46 \\
48 \\
52 \\
56 \\
58\end{array}$ & $\begin{array}{l}20.0 \\
20.0 \\
19.4 \\
20.0 \\
18.5 \\
18.5 \\
18.9\end{array}$ & $\begin{array}{l}11.9 \\
13.2 \\
12.6 \\
13.2 \\
11.3 \\
15.5 \\
17.4\end{array}$ \\
\hline 7 & $\begin{array}{l}40 \\
42 \\
44 \\
46 \\
50 \\
54 \\
56\end{array}$ & \begin{tabular}{l|}
20.0 \\
20.0 \\
20.0 \\
19.8 \\
17.6 \\
17.8 \\
17.8
\end{tabular} & $\begin{array}{r}7.4 \\
8.2 \\
6.8 \\
10.0 \\
10.4 \\
14.2 \\
16.0\end{array}$ \\
\hline
\end{tabular}

siderable individual variability in the specific delays at which discriminative performance was maintained above criteria (range 32-54 sec) and above chance (42-74 sec).

Second, the delays reported for criterion and abovechance performance for individual animals are in themselves averages of performance over the $S d$ and $S \Delta$ conditions. As noted, performance under these two conditions varied considerably, with subjects generally being more accurate following presentation of the Sd. Several possibilities exist for this difference. For example, during the initial shaping procedure, licking was reinforced following presentation of all tastes (see Response Shaping). Only during the discrimination phase of the study (see Phase 1: Discrimination Training) was the S $\Delta$ condition introduced and responding differentially reinforced. As a result of this preliminary training, there may have been a general bias to respond, which decreased the relative performance in the $S \Delta$ condition.

Although it is tempting to discuss the extent of the working memory for tastes on the basis of these findings, it is important to note that the delays reported in the present manuscript are markedly shorter than the delays reported in other assessments of taste memory in the rat, specifically the conditioned taste aversion paradigm (see Garcia \& Ervin, 1968; Revusky \& Garcia, 1970; Riley \& Tuck, 1985b; Rozin \& Kalat, 1971). In long-delay taste aversion learning, rats can acquire taste aversions when delays of 8 and $12 \mathrm{~h}$ separate ingestion of a specific taste and the administration of a toxin (see Nachman, 1970; Nachman \& Jones, 1974; Revusky, 1968; Riley et al., 
1984; Riley \& Tuck, 1985b; Smith \& Roll, 1967; see also Etscorn \& Stephens, 1973), suggesting an extended memory for tastes within this design. However, because of the many procedural differences between the delayed taste discrimination and taste aversion designs (for example, stimulus amount, duration, and familiarity, degree of interference, number of conditioning trials, and similarity or comparability of the reinforcer) conclusions regarding the basis for the differences in the extent of taste memory, for example, differential processing of the taste stimulus (see Bureš \& Burešova, 1977; Domjan, 1983, 1985; see also Garcia, Rusiniak, Kiefer, \& BermudezRattoni, 1982), must await further research.

\section{REFERENCES}

Biederman, G. B., Milgram, N. W., Heighington, G. A., StockMAN, S. M., \& O'NeILl, W. (1974). Memory of conditioned food aversion follows a U-shape function in rats. Quarterly Journal of Experimental Psychology, 26, 610-615.

Bureš, J., \& Burešova, O. (1977). Physiological mechanisms of conditioned food aversion. In N. Milgram, L. Krames, \& T. Alloway (Eds.), Food aversion learning. New York: Plenum Press.

Cohen, J. S., Escott, M., \& Ricciardi, P. (1984). The role of reinforcement symmetry and stimulus modality in successive delayed matching to sample in the rat. Canadian Journal of Psychology, $\mathbf{3 8}$, 63-79.

D'AмAто, M. R. (1973). Delayed matching and short-term memory in monkeys. In G. H.Bower (Ed.), The psychology of learning and motivation: Advances in research and theory (Vol. 7). New York: Academic Press.

D'AMATo, M. R., \& WORShAM, R. W. (1974). Retrieval cues and shortterm memory in capuchin monkeys. Journal of Comparative \& Physiological Psychology, 86, 274-282.

Domuan, M. (1983). Biological constraints on instrumental and classical conditioning: Implications for general process theory. In G. H. Bower (Ed.), The psychology of learning and motivation (Vol. 17). New York: Academic Press

Domin, M. (1985). Cue-consequence specificity and long-delay learning revisited. Annals of The New York Academy of Sciences, $\mathbf{4 4 3}$, 54-66.

Etscorn, F., \& StePhens, R. (1973). Establishment of conditioned taste aversions with a 24-hour CS-US interval. Physiological Psychology, 1, 251-253.

GARCIA, J., \& ERVIN, F. R. (1968). Gustatory-visceral and telereceptorcutaneous conditioning: Adaptation in internal and external milieus. Communications in Behavioral Biology, 1, 389-415.

Garcia, J., Ervin, F. R., \& Koelling, R. (1966). Learning with prolonged delay of reinforcement. Psychonomic Science, 5, 121-122.

Garcia, J., Rusiniak, K. W., Kiefer, S. W., \& BermudezRATTONI, F. (1982). The neural integration of feeding and drinking habits. In C. D. Woody (Ed.), Conditioning. New York: Plenum Press.

GraNT, D. S. (1982). Samples of stimuli, responses, and reinforcers: Effect of number, type, and mode of presentation. Learning \& Motivation, 10, 7-14.

Heise, G. A., Keller, C., Khavari, K., \& Laughlin, N. (1969). Discrete-trial alternation in the rat. Journal of the Experimental Analysis of Behavior, 12, 609-622.

Herman, L. M., \& Gordon, J. A. (1974). Auditory delayed matching in the bottlenose dolphin. Journal of the Experimental Analysis of Behavior, 21, 19-26.
Honig, W. K., \& Wasserman, E. A. (1981). Performance of pigeons on delayed simple and conditional discriminations under equivalent training procedures. Learning \& Motivation, 12, 149-170.

Klosterhalfen, S., \& KosterhalfeN, W. (1985). Conditioned taste aversion and traditional learning. Psychological Research, 47, 71-94.

LoGuE, A. W. (1979). Taste aversion and the generality of the laws of learning. Psychological Bulletin, 86, 276-296.

Mastropaolo, J. P., Dacanay, R. J., Luna, B., Tuck, D. L., \& RILEY, A. L. (1984). Effects of trimethyltin chloride on differentialreinforcement-of-low-rate responding. Neurobehavioral Toxicology \& Teratology, 6, 193-199.

NaChman, M. (1970). Learned taste and temperature aversions due to lithium chloride sickness after temporal delays. Journal of Comparative \& Physiological Psychology, 73, 22-30.

NaChman, M., \& JoNEs, D. R. (1974). Learned taste aversions over long delays in rats: The role of learned safety. Journal of Comparative \& Physiological Psychology, 86, 949-956.

Pontecorvo, M. J. (1983). Effects of proactive interference on rats' continuous nonmatching-to-sample performance. Animal Learning \& Behavior, 11, 356-366.

REvUSKY, S. H. (1968). Aversion to sucrose produced by contingent $\mathrm{X}$-irradiation: Temporal and dosage parameters. Journal of Comparative \& Physiological Psychology, 65, 17-22.

Revusky, S., GARCIA, J. (1970). Learned associations over long delays. In G. H. Bower (Ed.), The psychology of learning and motivation: Advances in research and theory (Vol. 4). New York: Academic Press.

Riley, A. L., Dacanay, R. J., \& Mastropaolo, J. P. (1984). The effect of morphine preexposure on the acquisition of morphine-induced taste aversions: A nonassociative effect. Animal Learning \& Behavior, 12, 157-162.

Riley, A. L., \& TuCK, D. L. (1985a). Conditioned taste aversions: A behavioral index of toxicity. Annals of the New York Academy of Sciences, 443, 272-292.

Riley, A. L., \& TuCK, D. L. (1985b). Conditioned food aversions: A bibliography. Annals of the New York Academy of Sciences, 443, 381-437.

RoberTs, W. A., GRANT, D. S. (1976). Studies of short-term memory in the pigeon using the delayed matching-to-sample procedure. In D. L. Medin, W. A. Roberts, \& R. T. Davis (Eds.), Processes of animal memory. Hillsdale, NJ: Erlbaum.

RoziN, P., KAlat, J. W. (1971). Specific hungers and poison avoidance as adaptive specializations of learning. Psychological Review, 78, 459-486.

RzosKA, J. (1954). The behavior of white rats towards poison baits. In D. Chitty (Ed.), Control of rats and mice (Vol. 2). Oxford: Clarendon Press.

SMITH, J. C., \& RoLL, D. L. (1967). Trace conditioning with X-rays as an aversive stimulus. Psychonomic Science, 9, 11-12.

SPIKER, V. A. (1977). Taste aversion: A procedural analysis and an alternative paradigmatic classification. The Psychological Record, 27, 753-769.

Wallace, J., Steinert, P. A., Scobie, S. R., \& Spear, N. E. (1980). Stimulus modality and short-term memory in rats. Animal Learning \& Behavior, 8, 10-16.

WESTBRoOK, R., Homewood, J. (1982). The effects of a flavourtoxicosis pairing upon long-delay, flavor aversion learning. Quarterly Journal of Experimental Psychology, 34B, 59-75.

(Manuscript received April 14, 1986; revision accepted for publication June 10, 1986.) 